\title{
Aspects of Sex Differences: Social Intelligence vs. Creative Intelligence
}

\author{
Ferdinand Fellmann' ${ }^{1}$, Esther Redolfi ${ }^{2}$ \\ ${ }^{1}$ Department of Philosophy, Chemnitz University of Technology, Chemnitz, Germany \\ ${ }^{2}$ Faculty of Humanities, University of Innsbruck, Innsbruck, Austria \\ Email: ferdinand.fellmann@phil.tu-chemnitz.de
}

How to cite this paper: Fellmann, F., \& Redolfi, E. (2017). Aspects of Sex Differences: Social Intelligence vs. Creative Intelligence. Advances in Anthropology, 7, 298317. https://doi.org/10.4236/aa.2017.74017

Received: September 3, 2017

Accepted: November 3, 2017

Published: November 6, 2017

Copyright (c) 2017 by authors and Scientific Research Publishing Inc. This work is licensed under the Creative Commons Attribution International License (CC BY 4.0).

http://creativecommons.org/licenses/by/4.0/

\begin{abstract}
In this article, we argue that there is an essential difference between social intelligence and creative intelligence, and that they have their foundation in human sexuality. For sex differences, we refer to the vast psychological, neurological, and cognitive science research where problem-solving, verbal skills, logical reasoning, and other topics are dealt with. Intelligence tests suggest that, on average, neither sex has more general intelligence than the other. Though people are equals in general intelligence, they are different in special forms of intelligence such as social intelligence and creative intelligence, the former dominant in women, the latter dominant in men. The dominance of creative intelligence in men needs to be explained. The focus of our research is on the strictly anthropological aspects, and consequently our explanation for this fact is based on the male-female polarity in the mating systems. Sexual dimorphism does not only regard bodily differences but implies different forms of sex life. Sex researchers distinguish between two levels of sexual intercourse: procreative sex and recreational sex, and to these we would add "creative sex." On all three levels, there is a behavioral difference between men and women, including the subjective experience. These differences are as well attributed to culture as genetically founded in nature. Sexual reproduction is only possible if females cooperate. Their biological inheritance makes females play a decisive role in mate choice. Recreational sex for the purpose of pleasure rather than reproduction results from female extended sexual activity. Creative sex, on the contrary, is a specifically male performance of sexuality. We identify creative sex with eroticism. Eroticism evolved through the transformation of the sexual drive into a mental state of expectation and fantasizing. Hence, sex differences (that nowadays are covered up by cultural egalitarianism) continue to be the evolutionary origin of the difference between social and creative intelligence.
\end{abstract}




\section{Keywords}

Forms of Intelligence, Emotional Intelligence, Creative Intelligence, Creative Sex, Evolution of Mating Systems, Eroticism, Orgasmic Pivot

\section{Introduction}

Intelligence research is not an easy field (Meyer, 2015: p. 257). The abstraction of intelligence as a single entity has been justly criticized since long (Heymans, 1910). The intelligence quotient does not measure a single faculty, but rather a bundle of mental abilities: sustainable interest, vivid fantasy, and careful choice of the subject, as well as talent, working memory, and calculation speed (Meyer, 2015). The main problem with intelligence tests is that thinking is connected with feeling, and as Sigmund Freud has remarked, feelings cannot be dealt with in a scientific way (Freud, 1948a: p. 422). With the introduction of the concept of emotional intelligence the question has become clearer. Intelligence as an inborn talent is a stable property in an individual, and the average levels of general intelligence are the same in men and women. But everyday experience shows that the minds of men and women are not identical, and that the relations between general intelligence and special intelligence differ.

Numerous investigations indicate that women are biologically adapted to perceive what others desire, intend, and know. Women's thinking is more bound to the emotional ego. Female self-awareness resulting from the presence of their culturally- and biologically-related body image is on its own, and permits of empathy or identifying with the feelings of others (Goleman, 1996: p. 112). Originally, empathy was seen as being distinct from sympathy, but researchers no longer make this distinction (Stueber, 2006). Empathy as the root of social intelligence has most likely contributed a great deal to shaping the female mind. On the other side, we maintain that creative intelligence has shaped the male mind. Men are more likely to distance their ideas from their individual feelings. Creative intelligence is adapted to exceptional ways of problem-solving, and the unexpected solutions often create new problems, which lead one even farther away from the starting point. There is much to suggest that the male mind, other than the female empathetic mind, is bound to the more constructive thought characteristic of systematic thinking. Of course, women are creative, but as a rule they show a higher degree of attachment, which as a consequence leads female creativity back to concrete matters.

At this point, we would like to make some remarks about how to read this article. Since we are philosophical anthropologists, our approach to understanding male and female intelligence is hermeneutical. Although hermeneutics does not rely on established data, it proves particularly useful because it refers to the natural background of cultural variables in an intuitive manner. More specifically, the fact that all human experience is medial, in a way, also holds for our state- 
ments. It is not merely the subject matter of our investigation that is gender ambivalent, but also its interpretation. Since every conclusion in this article is the result of the authors' mutual inspiration, readers should similarly follow this way of dealing with hard facts. Only by reading the text through the lens of our own sexual identity will we learn what indelible sex differences are good for: they are the basis for social coherence and understanding ${ }^{1}$.

\section{Part I: Two Types of Intelligence}

Our claim that men are more apt in creative intelligence, and that women are more aligned at social intelligence, needs scientific support. Neurobiology, psychology, and sociology have listed the sex differences in various forms of intelligence, beginning with the unconscious "wisdom of the body" and ending in sophisticated strategies to achieve a goal. Intersexual conflicts in "strategic interference" (Buss, 2009: p. 189) are programmed on every level of human behavior.

To begin with biology, Darwin in his pioneering work on sexology, Descent of Man and Selection in Relation to Sex (Darwin, 1871/2004), deals with sex differences in morphology and behavior. Sexual dimorphism as an effect of sexual selection in bodily and facial traits was neglected for a century and has been revitalized in modern evolutionary psychology and anthropology (Miller, 2000). Females invest much more physiologically in reproduction and in the care of their offspring than males, who invest more in attempts to attract and control prospective mates. Consequently, females are more "sophisticated," while males are more impulsive in their choice. In human life, acts of love are not products of particular cultures. Love is universal, and the primary biological function of sexual arousal is to signal commitment of reproductively-relevant resources. The female's more demanding choice causes women to be more precise in the investigation of fitness signals and makes them specialists in detecting false signals. With emotional support, women peruse their mating goals with more caution, psychological sensitivity, and tact. Men, on the contrary, come often fast and straight to the point with a great risk of being rejected (Buss, 2009). This difference specifies the well-known complexity of thinking and problem-solving attributed to humans.

Neuroscience has been a strongly worked field in the last decade (for an overview, see the publications of the Society for Neuroscience). The study of brain networks of men and women shows that the sexes excel in different abilities. As to creative intelligence, Goleman writes, "In a sense we have two brains, two minds and two different kinds of intelligence: emotional and rational" (Goleman, 1996: p. 32). Intelligence seems to be one of the most important criteria in partner selection (Meyer, 2015: p. 252). However, female and male brains show neurological differences (ibid.: p. 328f.; Fisher, 2004).

\footnotetext{
${ }^{1}$ Readers of the younger generation may well reject our explanations as not fitting their post-modern egalitarian way of looking at things. Although it is sometimes better to go with the flow rather than to change the natural course of social setting, we are striving to look underneath the surface and uncover persistent patterns of problem-solving behavior.
} 
In sociology, before the First World War 1, the German thinker Georg Simmel focused on forms of exchange. For Simmel the fundamentally dualistic character of social interactions has its base in the male-female polarity. Either sex is formed by the relation to the other sex, but there is a difference between men and women. In his article "The Relative and the Absolute in the Gender-Problem" Simmel presents an ambivalent gender construction (Simmel, 1911: pp. 65-103). Women have basic erotic needs, but in their way of feeling they are psychologically resting in themselves, which makes them less dependent on sexual activity. In consequence, their ability to achieve goals is more centripetal, whereas men are centrifugal in their activities. This position is confirmed by Max Scheler, who at nearly the same time, in an article "Shame and the Feeling of Shame," states that in women the tendency to objectivity is less developed than in men. The female by nature has a less expansiv, a more bound and ego-centered life. All thoughts, contents of perception and representation are not as strongly detached from bodily awareness and of the feeling of life as in men" (Scheler, 1957: p. 146; transl. FF). Finally, Scheler calls women "the proper genius of life" and men the "genius of spirit." Of course, Simmel's and Scheler's claims are intuitive and time-bound and now sound outdated, but in a fundamental sense they are still relevant.

After the Second World War, the German sociologist Helmut Schelsky in his Soziologie der Sexualität (1955) was much more bound to scientific research. In agreement with Margaret Mead, he asserts that ethnological material shows that most features generally called "male" and "female" are dissolved from biological sex differences (Schelsky, 1955: p. 26f.). On the other hand, he warns sociologists against the other tendency, to exaggerate and take as absolute the formal structures of social lives. He claims that social structures in the long run are meaningful answers to the biological nature of humans. This also applies to the formation of male and female intelligence. At the end of the $20^{\text {th }}$ century, sociology began to focus on cooperation. Success through collective work and cooperation has been called "social capital." Communitarian theory of social capital, mostly inspired by Putnam (1995), says that women can achieve any aim if they work collectively, fortifying the norms that underpin reciprocity, cooperation, and trust. It is assumed that an increase in social capital is characteristic of modern societies and supports female political participation and market efficiency. On the other hand, liberal theory assumes that social capital is inherently female, thus overlooking psycho-erotic hierarchies, power dynamics, and differences within communities and groups where an outstanding person is acknowledged as a leader. This way of acting can be supportive as well as dangerous for both sexes. There is a continuous dissolution and creative reconstruction of the will to social power, so that a society without sex differences and gender conflicts would no longer be a dynamic but a utopian society of stagnating egalitarianism.

From the psychological point of view, humans, a species with only moderate sex differences in structure, exhibit profound sex differences in the mind or psyche. It seems that in our century the differences are overthrown, but in earlier 
times there were more spaces of respect and mystery between men and women in the procedures of manners and of love. In women intelligence is associated with more pronounced feelings bound to subjective experiences. To use the words of John Stuart Mill, "a woman seldom runs wild after an abstraction." Men, on the contrary, are passionate about abstract material and consequently their intelligence functions without emotional restraint. The basic sex differences in mind have been listed by empirical research based on multiple tests loaded with fluid intelligence. This is the realm of evolutionary psychology, which was established in 1980 in the USA and is now recognized worldwide (Baron-Cohen, 2012; Geary, 2010; Wolpert, 2014).

In summary, empirical research demonstrates that sexual dimorphism can be an explanation for different mental approaches. Hence, social intelligence is more pronounced on the female side, whereas men excel in creative intelligence. In turn, social intelligence involves more directing than constructing, more learning and revising than fantasizing.

\subsection{The Biological Core of the Gender Gap}

Intellectual development depends on social environment and education, but this does not exclude the considerable genetic component at work. A newborn human is not a blank slate on which anything can be inscribed (Pinker, 2002). The social state is always prefigured by nature and consequently only retains the figures adapted to the biological ground. Notwithstanding the ideological mainstream's favoring of egalitarianism, modern societies still show sex differences that are not due to the notions of "proper role" or "natural place" assigned to women in patriarchal tradition. Nowadays female political leaders are conquering seats on supervisory boards and overtaking men in directing organizations. The blend of women's sense and sensibility is apt for this sort of social intelligence. Due to this state of mind, extraordinarily gifted women like Vandana Shiva are coming into view., The quantum physicist and recipient of the Alternative Nobel Prize is one of the world's foremost representatives of eco-feminism (Shiva \& Mies, 1993). Her goal is to bring the feminine perspective into the ecological discussion and to improve the social situation of women. Nevertheless, in science and art there is obviously a boundary line. To reach an extremely high level of creativity requires another state of mind, as creating is different from directing.

As far as literature is concerned," there are famous female writers, but as Virginia Woolf writes in $A$ Room of One's $O w n$, the insufficient number of outstanding female writers could be attributed to the social hurdles that they must overcome (Woolf, 1929). On the other side, revolutionary theories setting new aesthetic standards as did James Joyce," are rare. In art, the same is true at this point. For, in addition to a small number of female writers, the degree of recognition of exceptional female artists is not exactly high. One example is the 18th century painter Élisabeth Vigée-Lebrun (Monteil, 2004: p. 86f.), who is hardly known, despite her 660 portraits and 200 landscapes that are being exhibited in 
the most famous art galleries all over the world. $20^{\text {th }}$ century paintings by women as a rule look rather conventional. Great and innovative painters like Picasso are rather the exception among women.

In the sciences, although universities nowadays uphold equal employment policies to more female professors, women are still moving about on the middle level of average science research. Of course, men also remain on an average level of intelligence, and geniuses like Leonardo da Vinci or Einstein, who turned the standards of normal science upside down, are the exception. Leonardo, for example, had a sense of risk and an explorative curiosity that made the world look different to him as to normal people. Much there is to suggest that these exceptions are not random. They are, among other things, due to the nature of male sexual spontaneity.

It seems as if this eccentricity, typical of outstanding creative personalities, is not so common in women (but here again it must not be neglected that solitude and imagination, as Woolf claimed, are the wellsprings of creativity), who rather prefer to cooperate and to participate. Female intelligence excels in social interaction and curative behavior, in what we call "social intelligence." Each sex has its proper style of feeling and reasoning which is the natural ground of the individual figure. Here lies the biological core of the gender gap, which in the view of feminists is still a consequence of the traditional patriarchy, as the international "Women 20 Summit" suggests.

\subsection{The Sexual Paradox}

Nearly two centuries ago John Stuart Mill, in The Subjection of Women, attempted to make a case for perfect equality. Mill comments on three major facets of women's lives that he felt were impeding them: gender construction, education, and marriage. This was the case in the Victorian era, and the patriarchal component, to be sure, still plays a role in modern societies. Of course, female social intelligence must not be exercised exclusively in low-paid nursing careers, but can also be in prestigious professions such as those of doctors. But there is the paradox that female desires and devices are often contradictory. Hence, it is very difficult to find examples of social inequality that would exclude tradition and allow an unqualified access to the biological core. Susan Pinker, in her book The Sexual Paradox: Men, Women and the Real Gender Gap has focused on how sex differences play out in the workplace (2008). The results speak against some common feminist assumptions that the sexes are biologically equivalent and that men and women have identical interests and goals. After decades of educational coups and rising through the ranks, men still outnumber women in business, physical science, law, engineering, and politics. Independent reports suggest that women assess their workplace after a certain time as falling short for them. This shows that most likely subjection does not play a determining role.

One way of getting to the biological source is to compare weak boys who later succeed and high achieving women who opt out. If it is true that the majority of 
children with school and behavioral problems are boys, then why do so many men overcome early obstacles, while many high achieving women drop out at pivotal moments in their careers? The complete answer would be complex, but one point seems to be obvious: female and masculine minds differ essentially in the way of being in the world. Women usually tend, sometimes because of social conditions, to try to produce the greatest harmony among all sentient beings, whereas the impetuous acts of men often disregard the social consequences. This contrast is generally regarded as due to the struggle for life and the survival of the fittest. In the present, the opinion prevails that equality must not only be established in social rules, but also be founded in human nature which humanists consider to be essentially peaceful. Thus, the common belief in perfect equality would be the royal road to a world of eternal peace. But we, on the contrary, consider this to be an untenable image of humans, a dangerous anthropological error. We agree with the ethologist's view that man is a jeopardized creature and that aggression makes the difference (Lorenz, 1974). If all differences were erased, the world would end in a state of entropy. Hence, we claim that sex differences are vital for the functioning of human society and personal happiness.

Regarding the sex differences in mental disposition, we have to warn of a misunderstanding. It may seem as if men and women have opposite qualities: men are aggressive, egoistic, etc., whereas women are tender, altruistic, etc., but this is not our opinion. We are convinced that sex difference is found within the same trait. Men and women are both aggressive, but their aggression looks different and is expressed in different forms. Female aggression is subtler and often takes detours; it is generally agreed upon that women are less selfish. Furthermore, a consequence of the emancipation of women is the tolerant valuation of female behavior. Take the example of a marriage that is breaking up. The wife's decision to leave the marriage is usually considered as a step to self-realization; unless there are children involved; then the wife is seen as a bad mother. On the other hand, the husband's departure is usually judged negatively, as driven by basic instincts and by the search for sexual variety.

The same difference holds true for egoism and other traits, which Daniel Nettle (2011) discusses in his article "Evolutionary Perspectives on the Five-Factor Model of Personality". Nettle deals with two aspects of openness of mind: intelligence and artistic creativity, and he reports on sex differences in terms of neuroticism and agreeableness. In analogy to Nettle, it could be argued that there are sex differences regarding different types of intelligence. Of course, one must distinguish between different forms of intelligence: general, social, scientific, artistic, etc. This is difficult because intelligence as such is a matter of the whole personality, which is more than the sum of single traits. In this sense, our distinction between social and creative intelligence does not indicate separate psychological capacities but refers to different ways of expressing libidinal energy. In other words, we are dealing with different gender realizations of personality. Here the sexual paradox is being expanded to the paradox of subjectivity: being 
oneself and simultaneously being another, which will never be canceled out by one-dimensional social roles.

\section{Part II: Creative Intelligence Equals Eroticism}

We claim that the difference in cognitive functions is founded in sexual behavior and feeling. Despite his patriarchal ideology and lack of clinical evidence, Freud's theories of sexuality are still informative. He claimed that the human pursuit of happiness has its climax in sexual pleasure. For Freud "sexual" is not identical with "genital." For the newborn, the first sexual arousal is in sucking the mother's breast. The difference between male and female subjective experience begins in puberty. In a footnote of his Three Essays on the Theory of Sexuality (1905) Freud states that the meaning of male and female becomes most clear on the psychological level (Freud, 1948b: p. 121). The current view of the active male and passive female has to be specified. The life drive or libido is always active and thus basically male. But the application of the life drive differs. In females, the libidinous aim is passive in the sense of sexual surrender. Women do not lack activity in terms of sexual impact, so one may speak of an "active passivity" in sexual behavior. On the other hand, girls or young women are overwhelmed by male activity, which can cause them to repress the impact of their sexual drive and become the so-called "frigid woman." More information on the consequences of Freud's theory of female sexuality has been provided by the Austrian psychiatrist Otto Groß. In his monograph Die zerebrale Sekundärfunktion Groß (1902) interpreted the unconscious motives as part of the intellectual efficiency of what he called "the secondary cell function." For Groß the ways of problem-solving presuppose the secondary function as an equivalent of the unconscious working in the background. Hence female intelligence is linked to the unconscious, which is emotionally loaded.

\subsection{Subjective Experience}

This psychoanalytical background sheds new light on the male-female difference of sexual experience. Psychological introspection shows that the subjective experience is different on all levels of sexual intercourse. It is unfortunate that in order to define the quality of subjective experience we have to rely on metaphors as the only way to communicate feelings scientifically. Surely, language is a window into human nature (Pinker, 2007). But normal language is not sufficient. For many thoughts, we have no words. James Joyce invented new words to make the antagonistic sentiments in the male-female relation understandable: "Of a bodily and mental male organism specially adapted for the superincumbent posture of energetic human copulation and energetic piston and cylinder movement necessary for the complete satisfaction of a constant but not acute concupiscence resident in a bodily and mental female organism, passive but not obtuse" (Joyce, 1961: p. 732). The unspeakable is buried deep underneath the surface of our consciousness: love and hate, joy and grief are feelings which cannot be known 
purely from the behavioral surface, from the outside appearance-if only one could find the words.

For advances in an empirically orientated anthropology there are two problems with regard to subjective experience. First, it is difficult to decide which emotion is radical and which emotion is culturally constructed, since both influence each other. One does not know what one's own feelings are really like because of the interference of vanity and other causes of illusion. Second, we lack a clearly differentiated vocabulary to express the whole range of emotions. In any case, we must assume that in humans there exist far more types of emotion than the ones we are familiar with. The method of identifying them and making them communicable remains uncertain and fluctuates between experimental psychology and hermeneutic phenomenology. The ideal medium for the expression of emotions is poetry and literature in general.

To begin with procreative copulation where both partners are coming together, lust is already differently experienced because a woman feels as a potential mother. This is different from feeling as a potential father because of the uncertainty of fatherhood. The different quality is difficult to describe. The intensity of lust seems to be the same, but men experience sexual lust more aggressively, women more receptively as a fulfillment of a wish (in everyday language we are speaking of a "childless woman," but not of a "childless man"). And the next step, recreational sex, which modern women in 1968 made the hallmark of emancipation, is different. An example which confirms this is Erica Jong's (1973) term "zipless fuck" (a sexual encounter for its own sake, without emotional involvement, commitment, or any further motive between two unacquainted persons) coined in her novel Fear of Flying. On average, women are fully satisfied in sexual intercourse if the partner is an attractive man. To understand how satisfaction is felt, we refer to an informal survey among students ${ }^{2}$. The majority of the women said that the center of their feeling is the womb and not the heart, as romantic love pretends. Their body is filled with a sense of pleasure and their mind with joy. Men on the contrary reported that when climaxing they feel strong and at the same time a sense of relief. It seems that women and men feel differently due to the biological difference of the sexual organs. As to creative sex, we found the men were more inventive than women. Men fantasized about desired affairs, imagining how a sexual partner might become excited. This is different from female attraction and seduction. Men shape

${ }^{2}$ In January 2017 we interviewed forty students, twenty women, twenty men, all aged between 20 and 25. The first question was how they felt during sexual intercourse. All of them answered that they experienced sex as an intense pleasure. To the second question, as to the nature of their sexual feelings, women answered in a somewhat indefinite way. They reported that they felt good in their own skin, that they were comfortable. The male students, on the contrary, described their feelings more as a relief from a tormenting tension. To the third question, whether during sexual intercourse one is thinking about their partner's feelings, men answered yes; they want their partner to climax at the same time and feel as intensely as they do. Women reported that they are content if their partner orgasms, but honestly do not really care much about their partner's feelings. They expressed this in a somewhat apologetic tone. 
the sexual act in a more fantastic way than women. How such fantasies feel during sexual intercourse may be compared to the ambivalent feeling of a boy who imagines living in the jungle like Tarzan. The physical correspondence of erotic fantasy is the variety of copulation positions in which men are on the top.

To sum up, both sexes have their own strategies in expressing sexual desire; these strategies have to be flexible because the partner often undergoes unexpected changes of mood as a consequence of the male-female polarity. Men and women are looking for satisfaction in sexual intercourse. But the desire for sexual pleasure is not everything; it is complemented by an "effort after meaning" (Bartlett, 1995). "Meaning", in this context, refers to the connection of what is immediately felt with some expectation. Women wish and expect commitment; men wish and expect fidelity. This connection is pre-formed by the schema of Eros. Thus, the meaning of sexual intercourse meets the nature of eroticism.

\subsection{The Great Divide: Eroticism}

Eroticism is a transformation of sexual desire into a conscious mental state that is the foundation of the high intelligence of humans (Fellmann \& Walsh, 2016). In general, erotic representations are found in men and women alike. But on careful examination there are small but important sex differences. We claim that female erotic feeling is bound to concrete situations and thus representing the subjective point of view. Men's erotic figures on the contrary are more freefloating, as if seen by an objective observer. Erotic behavior is influenced strongly by culture, but modern erotic egalitarianism does not cancel out the notion that there are fundamental laws of sex differences in sexual life. The dynamics of the patriarchal ideology of the $19^{\text {th }}$ century do not apply any more in the democracies of the $21^{\text {st }}$ century. Nevertheless, the current brand of female emancipation seems to be an ersatz-patriarchism. Not our policies and our politics have led to the great divide, but the evolution of the mating mind.

Giacomo Casanova (2013) is the prototype of specific male eroticism, combining sensuality and spirituality. Casanova's eroticism is not centered on his own body but open to women in exquisite situations including feasts and games. This openness to the other sex is connected with Casanova's creative intelligence and sense of innovation. Casanova was recognized by his contemporaries as an extraordinary person, a man of far-ranging intellect and explorative curiosity. An example of specific female eroticism is provided by Anais Nin (1977). In her book Delta of Venus, published posthumously in 1977, and acclaimed by sex-positive feminists as a pioneering work, Nin explored fully the realm of erotic life, and certainly was one of the first prominent women in the modern West known to write female erotica. This is the mirror of her extraordinary, attractive personality. Nin was a friend, and in some cases lover, of many leading literary figures, including Henry Miller, with whom she shared a bohemian lifestyle during her time in Paris. 


\subsection{From Eroticism to Pornography}

Male eroticism often approaches the voyeur attitude and touches the border of pornography. To be sure, modern women too are pornographic, but female pornography is more genital-centered. Take the example of Charlotte Roche's pornographic novel Wetlands. The 18-year-old schoolgirl Helen has an unusual relationship to her body. She enjoys many of the bodily fluids secreted or excreted from it, be it mucus, pus, menstrual blood, but also men's sperm, all of which she "recycles" by putting them into her mouth and swallowing them. She loves to attract potential sexual partners by parading, underneath her dress, her unwashed vulva and the smells emanating from it. Falling in love with her male nurse she tries to draw the young man into her world. This behavior is not casual but the result of Helen's being lonely and bored since the breakup of her parents' marriage. Apart from this fact Helen's state of mind is the mirror of her body image. Here the relation between her erotic attitude and her restricted intelligence is obvious (Roche, 2009).

In contrast, traditional pornography, dominated by male fantasies, aims to subject women, but also shows a certain admiration, not of the individual woman but of womanhood ("das Weibliche") as such was the realm of men's yearning. Consequently, the much despised patriarchy is not a fate exclusively imposed on women by male domination in cultures. It has its origin in the male-female polarity and can be considered as the regular development of the patriarchally imprinted human culture, beginning with matriarchy and probably ending in a golden mixture of all possible styles of life hierarchies.

\subsection{The Limits of Gender Malleability}

The male-female polarity is founded in biology and cannot be eliminated totally by culture. This has been admitted by Margaret Mead, who, despite her early glorification of the malleability of gender, wrote as follows in the 1962 introduction to Male and Female: "I would, if I were writing it today, lay more emphasis on man's specific biological inheritance from earlier human forms and also on parallels between Homo sapiens and other than mammalian species" (Mead, 2001: p. XX). Biological inheritance regards the emotional attitude to the environment in situations of normal life which form the female role in public. Despite female's achievements, regardless of how she presents herself, she cannot remove the "eroto-sexual component." More than a man, the woman in her performances is linked to her sexual identity. This is not due exclusively to culture and not a result of male fantasy, but it is part of female self-awareness and of her self-presentation vis-à-vis both men and women.

Modern sociobiology attempts deliberately to integrate the psychoanalytical and social approaches. We would like to remind American readers of Karl Leonhard Instinkte und Urinstinkte in der menschlichen Sexualität (1964). Though Leonhard's conception of sex differences is half a century old, it contains important, yet neglected aspects regarding the sexual origins of creative in- 
telligence. He discusses the ambivalent feelings in erotic love and the struggle of the sexes (Leonhard, 1964: p. 59f.) $)^{3}$. Leonhard distinguishes between instincts and drives, the latter being the energetic force behind the instincts. The sexual drive seems to be stronger in men than in women, although female performance is lasting longer. There is a difference between the male and the female form of the sexual drive, which is apparent in the shape of the copulation process. Men show a jagged curve in successive orgasms, whereas the female curve is in waves (Leonhard, 1964: p. 272). As to the sexual instincts, Leonhard differentiates between the "domination instinct" of male activity and the "subordination instinct" of female receptivity (ibid.: p. 3). Female display and fashion is almost always corporal; the woman presents her body to be admired and taken. Men, on the contrary, do not feel their own body quite as directly, and the female body is an object of longing. This is the erotic source of male creativity. Leonhard admits that these oppositions may be changed especially by cultural practices. But he claims that the biological difference always surfaces, because the inborn image of the other sex is rigid and it directs the sexual emotions.

Regarding the sexual background of emotional intelligence feminists may object that modern women increasingly follow their way regardless sexual relations. The current slogan: "Follow your own way", suggests an arbitrary choice. Of course, one can choose a way of life without an intimate relation, and be content. Take the example of a priest or of an actress; the first with no sexual love at all, the latter with occasional sexual encounters. Both may be perfectly happy, since they have not experienced the pleasure of sexual pair-bond. Classical philosophers usually distinguish between two kinds of pleasure: bodily pleasure and mental pleasure. Modern phenomenology has replaced this dualistic view by differentiating between bodily pleasure of mere sensation and bodily pleasure combined with representations and expectations with regard to the partner. Who experiences the latter kind of pleasure will prefer it to futile enjoyment. Thus, a new experience of freedom will occur, namely to feel free with a partner in finding oneself through shared sexuality. This may enhance the own activities instead of impeding them, which is usually stated by emancipated women as the reason for rejecting a lasting love bond.

Already two decades ago the English novelist Philippa Gregory (1996) in her satire about feminism, Perfectly Correct, referring to D. H. Lawrence, The Virgin and the Gypsy, described the overcoming of the feminist conscious training by the sudden rise of sexual desire (pp. 9f.). She insists on sex differences in view of "genuine power". Men's genuine power is quite different from the exploitive and abusive power of patriarchy; it consists in activity, reliability, and commitment to the family (pp. 291ff.). This sounds rather traditional. Women's genuine ${ }^{3}$ Since 1957 the director of the psychiatric department at the Charité Hospital in East Berlin has in-
terviewed more than 2000 psychotic patients. Editors of Western journals rejected his papers be-
cause they were not in conformity with the standard practice of Anglo-American psychiatry. How-
ever he is well known for his classification of psychosis referred to as the Kleist-Leonhard classifica-
tion system. We refer to its theoretical presuppositions regarding sex differences in instincts and
their consequences for creative and social intelligence. 
power differs from the corresponding attitude of coquettishness that stirs male desire. But it is also different from the behavior pattern prescribed by feminist ideology, namely to behave as a non-sexual being. The genuine female power lies deeper in the inner life, it consists in sensitivity or sensibility, and in receptivity. Men's sensibility is more urgent, if one can speak of sensitivity at all ${ }^{4}$. The half-conscious emotional difference affects intelligence in the way we have shown.

\subsection{Life Is More than Survival}

It is interesting how the life histories of men and women are marked differently. Subjective experiences become moments, and some moments are more important than others. In the nunc stans, lived time passes beyond itself. Time is a relation of the present to the future and past, and this relation is lifted up in the "timeless time of Eros" (Fellmann, 2017). The bank of memory is the theme of Cecilia Ahern's novel Thanks for the Memories. Women are specialists in emotional memory. This is reminiscent of the Ecriture feminine, a theory which notes the relationship between the cultural and psychological inscription of the female body and female difference in language and text.

The German animal psychologist Werner Fischel, in his book Vom Leben zum Erleben (1967), distinguishes between life in the sense of surviving and life in the sense of subjective experience ${ }^{5}$. Subjectivity has led to human self-consciousness. In evolution, consciousness has become an end in itself because it produces mental contents that are stored in the memory bank. Regarding the human feeling of true love, it is not bound to momentary satisfaction in the present, as in animals, but directed to a common future (Fischel, 1967: p. 122). The heightened sexual responsiveness in pair-bond intimate communication has changed how the brain functions. It is no longer an instrument for focusing the mind on the problems of physical adaptation. The lowering of the physical efficiency of the brain permitted the development of mental faculties which possess no direct survival value. Biologically nearly useless, but spiritually valuable mental states are at the root of personal consciousness. Fischel calls this the theory of "cerebral existential enrichment" (ibid.: p. 126). This enrichment is now known as the “emotional brain" (Ledoux, 1996).

\subsection{Paving the Way}

It is helpful at this point to glance at the history of modern theories of sex differences. One landmark theory is that of Wilhelm von Humboldt, who gave an outline of comparative anthropology, combining enlightenment and romantic ideas. In his articles "Über den Geschlechtsunterschied" and "Über die männliche und

${ }^{4}$ Take the example of a man who is caring about the baby in the way mothers do. In public a man who is pushing a stroller may show a feeling of pride because he conforms to the new stereotype of behavior in the sense of gender equality. But if he is drawn to reflect about his state of mind, he probably will become aware of his underground male potency.

${ }^{5}$ Similar to Leonhard, Fischel's work has not been recognized by modern psychology in consequence of his ideological burden as alleged Nazi and communist. 
weibliche Form" he envisaged the purpose of the modern state as enabling its citizens fully to realize their human vocation (Humboldt, 1960). It would be necessary for this purpose, according to Humboldt, to accord a positive value to human sensuality and give it a freer and more creative rein. Consequently, he rejected the traditional dualistic view of human nature with its mind/body dichotomy and the Cartesian notion of the human spirit as a kind of ghost in the machine. Instead, so he maintained, mind and body form a vital unity, and what metaphysicians had called "spirit" for him was nothing but the finest development of sensuality. The path to self-determination that Kant had demanded in his moral philosophy must therefore proceed through the cultivation of human sensuality. Hence the realm of aesthetics is granted a key function in any attempt to overcome the inherited mind-body dichotomy, in which Humboldt saw a major obstacle in the path of achieving individual self-determination. In his two contributions to Friedrich Schiller's journal Die Horen, Humboldt took the additional step of characterizing sexual difference as basic biological and anthropological givens of human culture and society.

Another landmark is the work of the German philosopher of life, Arthur Schopenhauer. For him the organic world is the phenomenal appearance of the will to live. The will to live as an unconscious restless striving and as a permanent yearning is the absolute reality behind the natural world (Schopenhauer, 1966). The will manifests itself primarily in the human body. Schopenhauer calls the body an "immediate object" because it is experienced as an object and at the same time as an inner force. Schopenhauer reports no sex difference in bodily experience. But recent research has shown that girls, more so than boys, identify themselves with their sex, and that women show a stronger identification with their body image (Tiemersma, 1989: p. 65f.). Women, one could argue, are nearer to the will to live, and as a consequence they are feeling and thinking in a more concrete way than men. In Schopenhauer's words, the will to live objectifies itself in men at a higher level of abstraction. This difference lies at the root of the body-based sex difference in creative and social intelligence.

In view of our era of social egalitarianism, the reading of these traditional works is like falling back into a past world. But we must not forget the fact that the world is subjected to natural laws that change slowly if ever. Bodily and mental sex differences are the result of the natural norm of genetic reciprocity. The sexual dimorphism causes women to invest in more bodily substance than men for the continuance of life, and that is the ultimate cause why women's ways of feeling and reasoning remain nearer to the genes. Men's procreation investment is modest, hence their capacity to generalize and to construct mental models detached from the issues of sexual identity. On the other hand, men are more perturbed by the sexual impulse than women. Even in modern societies, where there is little repression in sexual life, men's eroticism at times heightens creative intelligence. In the future, embodied cognition may eventually lead via the extended mind to artificial intelligence, which is completely gender neutral 
(Shapiro, 2014).

\section{Part III: Emotional Selection and the Origins of Creative Intelligence}

In this part, we consider the evolution of the two forms of intelligence resulting from the male-female polarity in sexual behavior. Evolution explains how humans are more intelligent in a qualitative sense than non-human primates. The traditional hypothesis refers to the upright gait, tool-making, and using artificial weapons as means to survive in hostile environment as key elements. Our position is different. In our opinion, intelligence evolved through the male-female difference in the subjective experience of sexual behavior.

Biologists have reconstructed in detail the evolution of human sexuality (Symons, 1981). Darwin, who has made sexual selection a corollary to natural selection, deals with difference in the mental powers of the two sexes (Darwin, 2004: p. 629ff.). To be sure, Darwin adheres to Victorian patriarchal ideology, which assigned women their "proper" place in family life. Against Mill's book On the Subjection of Women, Darwin used a farmyard analogy to explain female inferiority. He admits that women perceive and feel more rapidly than men-traits which he held to be characteristic of the lower races and therefore a relic of a past state of civilization. From today's perspective, this sounds scandalous. Nevertheless, Darwin traced mental sex difference back to sexual selection, which is still an idea worth considering. He refers to the law of battle in the animal world, where males are bound to conquer a female (ibid: pp. 627ff.). This was still the case in early hunter-gatherer cultures, and caused a great spirit of emulation among male youths. Females, on the other hand, were the selectors, and the female choice formed women's mental powers in detecting signs of good genes and parenting behavior. In later times, when marriage became the official form of living together, a double form of female and male selection seems to have occurred (ibid.: p.668). Here is the interesting point where, from the evolutionary point of view, Darwin is shifting from mere bodily to mental and sentimental sexual dimorphism.

In following Darwin, modern anthropologists claim that mutual choice has shaped the human mind (Miller, 2000). Recently "emotional selection" has been proposed as a special form of sexual selection connected with long-term personal relations (Fellmann \& Walsh, 2013). We suggest that the pair-bonded state divided the human mind into female emotional intelligence and male abstract intelligence, which are mutually reinforcing. Emotional selection differs from sexual selection in the way that qualities such as kindness, mind-reading, and a sense of humor are valued more highly than physical fitness alone. Face-to-face copulation is closely linked to the identity signals from the partner and makes sexual intercourse personalized sex. Face-to-face contact matters: tight bonds of love have extended human lives and make humans happy (Pinker, 2014). Less intimate bonds with others matter, too; these are combined with our close rela- 
tionships to form a personal "village" around us, one that produces unique effects. Not just any social network will do: we need the real, in-the-flesh encounters that tie human families, groups of friends, and communities together. In intimate relations of long term pair-bonding the sexual drive has become so sensitive, so highly developed, so varied in its manifestations, that it raises men and women up to experience higher order emotions unknown to animals. This is not some kind of sophisticated deviation of modern culture, but a biologically-based and evolutionary normal tendency of human consciousness (Damasio, 1999).

\subsection{Ways of Learning}

The anthropologist Michael Tomasello $(1999,2014)$ has explained the difference between animal and human intelligence in his two books The Cultural Origins of Human Cognition and A Natural History of Human Thinking. His core thesis reads: "The crucial difference between human cognition and that of other species is the ability to participate with others in collaborative activities with shared goals and intentions" (passim). This thesis corresponds to the cultural mainstream of the 1990s, which sees humans as altruistic beings with communicative sensibility. Regarding evolution, Tomasello refers to learning from each other. He distinguishes two forms of learning: emulative learning and imitational learning, the latter being exclusively performed by humans.

For the evolution of imitational learning, Tomasello does not mention sexual selection, and it also seems that he sees no male-female difference in the emergence of human learning and intelligence. He refers to a somewhat obscure mediating power like libido that has been the driving force in human evolution. We, on the contrary, claim that the driving force consists in the reciprocity of emotional contact according to the libidinal structure of the body schema. Emotional selection is a two-step process of adaption to and learning from the sexual partner. To understand the driving mechanism of emotionality, we have to clarify the nature of human emotions first.

\subsection{Higher-Order Emotions}

Whereas evolutionary psychology focuses almost exclusively on mating strategies, the primatologist Frans de Waal focuses on the emotional features of intersubjectivity. Surprisingly he makes no substantial distinction between animal and human emotions (de Waal, 2011). We, on the contrary, claim that higher-order emotions like hope, love, and despair are exclusively human. In higher-order emotions one becomes aware of one's individual decisions and choices (Frankfurt, 1995, 2004). This is shown by a community with imitational learning. In human mating systems, female choice is replaced by mutual choice. This is a step toward egalitarianism, but the mutuality is not symmetric. As women are by nature procreative beings and potential mothers their choice will be motivated by other criteria than by the criteria of men. As a consequence the higher-order emotions are felt differently by men and women. Female hope, for ex- 
ample, is directed to more concrete aims, whereas male hope concerns great expectations which can be easily replaced by different ones. Here, Pandora's Box may be mentioned as a mythological example. As to love, the difference is more subtle because of the romanticism of "true love" which unites a pair. But even in love the female erotic response is more focused on the individual partner than the male which is focused on the general female body image.

Do human mental qualities emerge as a consequence of higher intelligence during evolution? We think it is the other way round: Intelligence developed piece by piece through the combination of individual and social capacities. Emotional selection as the subjective side of sexual selection reinforces the sex difference in intelligence. For subjectivism, knowledge emerges on the emotional level, where there is no objective and gender-neutral test of truth. This model of emotional evolution is analogous to sexual reproduction, the advantage of which consists in producing genetic varieties apt to survive in changing environments. These varieties do not only concern physiological properties but also psychological ones combined with enhanced intellectual abilities. The combination of hard and soft ways of adaptation ensures successful dealing with changing situations in a world made by humans.

\subsection{The Orgasmic Pivot}

An alternative approach to emotional selection in evolution refers to the relative parental investment of the sexes in their children. Feminist writers such as Sarah Blaffer (2009) Hrdy argue that female care has been the key for cultural evolution. This supports our emotional selection hypothesis that women excel in social intelligence. On the other hand, the so-called "sex contract" does not fall short. Instead we claim that the close erotic connection of two individuals in a long-time pair-bonding state is the pivot of sex differences in subjective experiences. In light of the different levels of emotionality, it becomes manifest that the cooperative alloparenting and the pair-bond model may have evolved together. In the general discussion of the evolution of emotionality, Randy Thornhill (2008, p: 277f.) and Steven Gangestad note that women are more emotionally expressive than men but at the same time possess greater ability to control the expression of emotions.

To understand how the difference between social and creative intelligence evolved in sexual life, the widely discussed topic of female orgasm may be helpful. In orgasm Eros cancels chronological time. But lived time of orgasm is different for men and women. The difference results from the biological fact that for men orgasm occurs during ejaculation, whereas female orgasm seems to be a byproduct of sexual intercourse (Dixson, 2009: p. 77; Symons, 1981). Men have much raw passion focused in a moment, followed by a refractory period. In this detached moment intelligence is at its creative climax. Women are capable of multiple orgasms, which cause a feeling of flow. This feeling of floating harmony in erotic response is the counterpart of social intelligence. Although orgasm 
seems to be an inconspicuous element of normal sexuality, it is highly relevant for sex differences in eroticism. It confirms what Margaret Mead has called "Potency and Receptivity" in order to stress the difference in the social coining of the male-female polarity reflected in the outcomes of intelligence (Mead, 2001: pp. 167-206).

\section{Conclusion}

Looking back at the path of our argumentation, we discern the following three stages.

First, we presented and discussed sex differences in extended intelligence which are empirically listed by various life sciences. The forms of intelligence are culturally shaped, but they have a biological basis in sexual dimorphism. The acknowledgement of sex differences is difficult for current egalitarianism. Despite such postmodern way of seeing, our thesis is that the male-female polarity is fundamental for social coherence and harmony.

Second, it is undeniable that both sexes are driven by unconscious forces, the libido. The unconscious is the ground of the different figures of male and female intelligence. Men have the tendency to liberate themselves from the dominance of the emotional ground in a different way than women. Men are leaving the unconscious behind through fantasizing. Women's intelligence on the other hand remains nearer to emotionality and thus gains an increased vitality for social behavior.

Third, the pair-bond theory of human evolution confirms our hypothesis that the various forms of intelligence have evolved through sexual behavior. As a consequence of the sexual revolution of 1968 , it seems that sexuality is no longer an existential problem in modern societies. Of course, many rules have changed for the better, but on the whole, we are convinced that human intelligence still has its "darkest Africa". The heart of darkness consists in sex differences and conflicts which cannot be ignored by anyone who is honestly trying to understand the world in which we humans live.

\section{References}

Baron-Cohen, S. (2012). The Essential Difference. New York, NY: Penguin.

Bartlett, F. C. (1995). Remembering. A Study in Experimental and Social Psychology. Cambridge: Cambridge University Press. https://doi.org/10.1017/CBO9780511759185

Blaffer Hrdy, S. (2009). Mothers and Others. The Evolutionary Origins of Mutual Understanding. Cambridge: Harvard University Press.

Buss, D. M. (2009). Evolutionary Psychology: The New Science of Mind. Boston: Pearson.

Casanova, G. (2013). Histoire de ma vie. Paris: Gallimard.

Damasio, A. R. (1999). The Feeling of What Happens. Body and Emotion in the Making of Consciousness. New York, NY: Harcourt.

Darwin, C. (2004). The Descent of Man, and Selection in Relation to Sex. London: Penguin.

De Waal, F. B. M. (2011). What Is an Animal Emotion? Annals of the New York Acad- 
emy of Sciences, 1224, 191-206. https://doi.org/10.1111/j.1749-6632.2010.05912.x

Dixson, A. F. (2009). Sexual Selection and the Origins of Human Mating Systems. Oxford/New York, NY: Oxford University Press.

Fellmann, F. (2017). Memory and the Timeless Time of Eros. Psychology, 8, 963-977. https://doi.org/10.4236/psych.2017.87063

Fellmann, F., \& Walsh, R. (2013). Emotional Selection and Human Personality. Biological Theory, 7, nr. 2. https://doi.org/10.1007/s13752-013-0093-3

Fellmann, F., \& Walsh, R. (2016). From Sexuality to Eroticism: The Making of the Human Mind. Advances in Anthropology, 6, 11-24. https://doi.org/10.4236/aa.2016.61002

Fischel, W. (1967). Vom Leben zum Erleben. München: Johann Ambrosius Barth. https://doi.org/10.1007/978-3-642-88666-9

Fisher, H. (2004). Why We Love? The Nature and Chemistry of Romantic Love. New York, NY: Griffin.

Frankfurt, H. G. (1995). The Importance of What We Care About. Philosophical Essays. Cambridge/New York, NY: Cambridge University Press.

Frankfurt, H. G. (2004). The Reasons of Love. Oxford: Princeton.

Freud, S. (1948a). Gesammelte Werke XIV. London: Imago.

Freud, S. (1948b). Gesammelte Werke V. London: Imago.

Geary, D. C. (2010). Male, Female. The Evolution of Human Sex Differences. Washington DC: American Psychological Association. https://doi.org/10.1037/12072-000

Goleman, E. (1996). Emotional Intelligence. Why It Can Matter More than IQ. New York, NY: Bantam Books.

Gregory, P. (1996). Perfectly Correct. London: HarperCollins.

Groß, O. (1902). Die zerebrale Sekundärfunktion. Leipzig: F. C. W. Vogel.

Heymans, G. (1910). Die Psychologie der Frauen. Heidelberg: Carl Winter.

Humboldt von, W. (1960). Schriften zur Anthropologie und Geschichte. Darmstadt: Wiss. Buchgesellschaft.

Jong, E. (1973). Fear of Flying. New York, NY: Holt, Rinehart and Winston.

Joyce, J. (1961). Ulysses. New York, NY: Vintage Books.

Ledoux, J. (1996). The Emotional Brain: The Mysterious Underpinnings of Emotional Life. New York, NY: Simon and Schuster.

Leonhard, K. (1964). Instinkte und Urinstinkte in der menschlichen Sexualität. Stuttgart: Ferdinand Enke.

Lorenz, K. (1974). On Aggression. London: Mariner Books.

Mead, M. (2001). Male and Female, with an Introduction by Helen Fisher. London: Perennial.

Meyer, A. (2015). Adams Apfel und Evas Erbe. Wie die Gene unser Leben bestimmen und warum Frauen anders sind als Männer. München: C. Bertelsmann.

Miller, G. F. (2000). The Mating Mind. How Sexual Choice Shaped the Evolution of Human Nature. New York, NY: Random House.

Monteil, C. (2004). The Beauvoir Sisters: An Intimate Look at How Simone and Hélène Influenced Each Other and the World. Emeryville, CA: Seal Press.

Nettle, D. (2011). Evolutionary Perspectives on the Five-Factor Model of Personality. In D. M. Buss, \& P. H. Hawley (Eds.), The Evolution of Personality and Individual Differences. New York, NY: Oxford University Press. 
Nin, A. (1977). Delta of Venus. New York, NY: Harcourt Brace Jovanovich.

Pinker, St. (2002). The Blank Slate. The Modern Denial of Human Nature. London: Penguin.

Pinker, St. (2007). The Stuff of Thought. London: Penguin Books.

Pinker, Su. (2008). The Sexual Paradox. Men, Women, and the Real Gender Gap. New York, NY: Scribner.

Pinker, Su. (2014). The Village Effect: How Face-to-Face Contact Can Make Us Healthier, Happier, and Smarter. New York, NY: Random House Canada.

Putnam, R. D. (1995). Bowling Alone: America's Declining Social Capital. Journal of Democracy, 6, 65-78. https://doi.org/10.1353/jod.1995.0002

Roche, Ch. (2009). Wetlands. New York, NY: Grove Press.

Scheler, M. (1957). Schriften aus dem Nachlass, Band I. Bern: Francke Verlag.

Schelsky, H. (1955). Soziologie der Sexualität. Reinbek bei Hamburg: Rowohlt.

Schopenhauer, A. (1966). The World as Will and Idea. New York, NY: Dover Publications.

Shapiro, L. (2014). The Routledge Handbook of Embodied Cognition. London \& New York, NY: Routledge.

Shiva, M., \& Mies, M. (1993). Ecofeminism. London, New York, NY: Zed Books.

Simmel, G. (1911). Philosophische Kultur. Gesammelte Essais. Potsdam: Gustav Kiepenheuer.

Stueber, K. (2006). Rediscovering Empathy. Cambridge: MIT Press.

Symons, D. (1981). The Evolution of Human Sexuality. Oxford: Oxford University Press.

Thornhill, R., \& Gangestad, S. W. (2008). The Evolutionary Biology of Human Female Sexuality. New York, NY: Oxford University Press.

Tiemersma, D. (1989). Body Schema and Body Image. An Interdisciplinary and Philosophical Study. Amsterdam/Lisse: Swettz \& Zeitlinger.

Tomasello, M. (1999). The Cultural Origin of Human Cognition. Cambridge: Harvard University Press.

Tomasello, M. (2014). A Natural History of Human Thinking. Cambridge: Harvard University Press. https://doi.org/10.4159/9780674726369

Wolpert, L. (2014). Why Can't a Man Be More Like a Woman? New York, NY: Skyhorse Publishing.

Woolf, V. (1929). A Room of One's Own. London: Penguin. 